\title{
A nonlabeled method to evaluate cortisol production rate by modeling plasma CBG-free cortisol disposition
}

\author{
N. PICARD-HAGEN,${ }^{1}$ V. GAYRARD,${ }^{1}$ M. ALVINERIE,${ }^{2}$ H. SMEYERS,${ }^{1}$ \\ R. RICOU, ${ }^{1}$ A. BOUSQUET-MELOU ${ }^{1}$ AND P. L. TOUTAIN ${ }^{1}$ \\ ${ }^{1}$ Unité associée Institut National de la Recherche Agronomique de Physiopathologie et Toxicologie \\ Expérimentales, Ecole Nationale Vétérinaire de Toulouse, 31076 Toulouse; and ${ }^{2}$ Institut National \\ de la Recherche Agronomique Station de Pharmacologie, 31300 Toulouse, France
}

Received 14 November 2000; accepted in final form 14 June 2001

\begin{abstract}
Picard-Hagen, N., V. Gayrard, M. Alvinerie, H. Smeyers, R. Ricou, A. Bousquet-Melou, and P. L. Toutain. A nonlabeled method to evaluate cortisol production rate by modeling plasma CBG-free cortisol disposition. Am J Physiol Endocrinol Metab 281: E946-E956, 2001.-This study aimed to develop a nonlabeled method for the measurement of cortisol production rate to evaluate adrenal function. The cortisol production rate determination requires that of cortisol clearance, which is not a parameter but a variable resulting from the saturable binding of cortisol to corticosteroidbinding globulin (CBG). Our method is based on evaluation of the plasma clearance of the CBG-free cortisol fraction. This parameter was evaluated from a pharmacokinetic model of total plasma cortisol disposition that takes into account specific binding of the corticoid to CBG in the plasma. We have shown that the CBG-free cortisol kinetics and CBG-binding parameters thus evaluated are not statistically different from those obtained by the radioisotopic method and equilibrium dialysis, suggesting that the plasma CBG-free cortisol clearance is independent of the total plasma cortisol concentrations and represents the actual parameter of cortisol elimination. We validated this modeling approach by using it to calculate the in vivo entry rate of cortisol mimicked by the perfusion of cortisol at a known rate.
\end{abstract}

cortisol disposition; ovine; corticosteroid-binding globulin

ADRENAL FUNCTION has been evaluated extensively by measuring the cortisol production rate in physiological and pathological states in humans $(3,10,12,13)$ and in different species, including ewes $(17,18)$. However, conflicting results have been obtained, depending on the methodological approach used $(5,24)$. The method based on the evaluation of plasma cortisol clearance is hindered by the nonlinear disposition of cortisol resulting from its specific and saturable binding to corticosteroid-binding globulin (CBG). In many species, including ewes, the maximal CBG-binding capacity is of the same order of magnitude as the maximal plasma physiological cortisol concentration (6). If it is assumed that only the cortisol fraction unbound to CBG can be cleared from the plasma, then the ultradian rhythmic-

\footnotetext{
Address for reprint requests and other correspondence: P. L. Toutain, Laboratoire de Physiologie \& Thérapeutique, Ecole Nationale Vétérinaire de Toulouse, 23 chemin des Capelles, 31076 Toulouse (E-mail: pl.toutain@envt.fr).
}

ity of cortisol secretion will result in instantaneous and permanent variations of this metabolizable cortisol fraction. Thus the plasma cortisol clearance evaluated by radioisotopic methods is not a parameter but a variable, exhibiting episodic and circadian fluctuations that will depend on the current total plasma cortisol concentrations. In contrast, the plasma CBG-free cortisol clearance (i.e., clearance of cortisol unbound to CBG) will be independent of the fluctuations in cortisol concentrations and should represent the actual parameter of cortisol elimination.

In the present paper, we propose to develop and validate a method of measuring the plasma CBG-free cortisol clearance on the basis of an in vivo modeling approach that takes into account the specific binding of cortisol to CBG. This approach enables the CBG-free cortisol disposition, CBG-binding parameters, and a cortisol production rate to be determined from the plasma profile of CBG-free cortisol concentrations.

\section{MATERIALS AND METHODS}

\section{General}

Nine Lacaune ewes (3-9 yr old), weighing $57.6 \pm 6.6 \mathrm{~kg}$, were used. They were kept in a light-sealed room under an artificial photoperiod (12:12-h light-dark cycle) in individual metabolism cages and received daily rations of concentrate. Hay and water were given ad libitum.

\section{Design}

Dexamethasone was administered intravenously at 0700 , during each experiment, i.e., $3 \mathrm{~h}$ before exogenous cortisol administration, to suppress endogenous cortisol secretion.

Experiment 1 was designed to evaluate the plasma CBGfree cortisol kinetics and CBG-binding parameters by modeling the disposition of exogenous total plasma cortisol concentrations after intravenous administration of cortisol at 3 dose levels $(0.05,0.2$, and $1 \mathrm{mg} / \mathrm{kg})$ in a crossover design involving nine ewes. The blood-sampling schedule was determined from preliminary studies performed in horses (14) or in ewes (7) that enabled the pharmacokinetic parameters and predictive concentrations to be obtained. In addition, periph-

The costs of publication of this article were defrayed in part by the payment of page charges. The article must therefore be hereby marked "advertisement" in accordance with 18 U.S.C. Section 1734 solely to indicate this fact. 
eral blood samples were collected during a large period postadministration to guarantee that, for the last samples, cortisol concentrations were under the level of quantification of the RIA.

During each treatment, which was separated by a washout period of at least 7 days, cortisol was administered intravenously at 1000 . Peripheral blood samples were collected at 1-h intervals for $3 \mathrm{~h}$ before cortisol administration; at 1, 2, 4, $8,15,30,45$, and $60 \mathrm{~min}$; and then at 1-h intervals until $9 \mathrm{~h}$ postcortisol administration.

Experiment 2 was designed to compare the plasma CBGfree cortisol kinetics and CBG-binding parameters obtained in experiment 1 (modeling approach) with reference values. The reference values for plasma CBG-binding parameters were obtained using equilibrium dialysis. A radioisotopic method was adapted to measure the control value for plasma CBG-free cortisol clearance. The radioisotopic method was performed with six ewes from experiment $13 \mathrm{~h}$ after a dexamethasone injection. $\left[{ }^{3} \mathrm{H}\right]$ cortisol was administered intravenously at 1000 . Peripheral blood samples were collected at 1-h intervals for $3 \mathrm{~h}$ before and after $\left[{ }^{3} \mathrm{H}\right]$ cortisol administration at $1,2,4,8,15,30,45$, and $60 \mathrm{~min}$ and then at 1 -h intervals until $12 \mathrm{~h}$ postadministration.

Experiment 3 was performed with the six ewes from experiment 2 to validate the proposed method of estimation of cortisol production rate from the values of the plasma CBGfree cortisol clearance and the area under the plasma CBGfree cortisol concentration-time curve. For this, the method was applied to an experimental situation during which the cortisol production rate was mimicked by the intravenous perfusion of cortisol at a known rate. During the first trial, ewes received two successive perfusions of cortisol at the rates of 1.6 and $12 \mathrm{mg} / \mathrm{h}$ for $5 \mathrm{~h}$. During a second trial $8 \mathrm{mo}$ later, the same ewes received three successive perfusions of cortisol at the rates of $0.27,2.7$, and $18 \mathrm{mg} / \mathrm{h}$ for $4 \mathrm{~h}$. The endogenous cortisol secretion was suppressed by the administration of dexamethasone at 0700 , i.e., $3 \mathrm{~h}$ before the beginning of the first perfusion. Peripheral blood samples were collected at 1-h intervals for $3 \mathrm{~h}$ before the start of the first cortisol perfusion and at 20-min intervals during the perfusions.

Protein binding. Blood samples $(50 \mathrm{ml})$ were obtained by venipuncture of the left jugular vein before the experiments to measure the in vitro plasma protein binding of cortisol. The endogenous corticoids were removed from the plasma by adsorption on charcoal (2). In vitro protein binding of cortisol was measured at $37^{\circ} \mathrm{C}$ over a wide range of concentrations $(0.005-2.762 \mu \mathrm{M})$ by equilibrium dialysis using a Dianorm system (CH8135; Langenau, Zurich, Switzerland), as previously described by Gayrard et al. (6).

Administrations and blood sampling. All drugs were injected in the right jugular vein via an indwelling catheter that had been inserted the day before the experiments. Dexamethasone (Cortamethasone; Vetoquinol, Lure, France) was administered intravenously at a dosage of $0.1 \mathrm{mg} / \mathrm{kg}$. For experiment 1, cortisol (hydrocortisone; Sigma, l'Isle d'Abeau Chesnes, La Verpillière, France) was dissolved in DMSO and ethanol $(50: 50, \mathrm{vol} / \mathrm{vol})$ to produce respective concentrations of $1.75(0.05 \mathrm{mg} / \mathrm{kg}), 7(0.2 \mathrm{mg} / \mathrm{kg})$, and $35(1 \mathrm{mg} / \mathrm{kg}) \mathrm{mg} / \mathrm{ml}$. For experiment 3, cortisol was dissolved in ethanol and saline to produce concentrations of $0.09 \mathrm{mg} / \mathrm{ml}(10: 90, \mathrm{vol} / \mathrm{vol}, 0.27$ $\mathrm{mg} / \mathrm{h}), 0.4 \mathrm{mg} / \mathrm{ml}(10: 90$, vol$/ \mathrm{vol}, 1.6 \mathrm{mg} / \mathrm{h}), 0.9 \mathrm{mg} / \mathrm{ml}(10: 90$, $\mathrm{vol} / \mathrm{vol}, 2.7 \mathrm{mg} / \mathrm{h})$, and $3 \mathrm{mg} / \mathrm{ml}(25: 75$, vol/vol, $12 \mathrm{mg} / \mathrm{h})$. To produce a $6 \mathrm{mg} / \mathrm{ml}$ cortisol solution, cortisol was dissolved in DMSO, ethanol, and saline (37.5:2.5:60, vol/vol/vol, $18 \mathrm{mg} / \mathrm{h})$.

$\left[1,2,6,7-{ }^{3} \mathrm{H}\right]$ cortisol was purchased from Amersham International (Buckinghamshire, UK) in toluene-ethanol (9:1, vol/ vol). The specific activity was $63 \mathrm{Ci} / \mathrm{mmol}$, and the radiochemical purity was $>99 \%$. The solution was evaporated to dryness with nitrogen gas. Five milliliters of DMSO were added to the residue. $\left[1,2,6,7-{ }^{3} \mathrm{H}\right]$ cortisol was administered at a dosage of $5 \mu \mathrm{Ci} / \mathrm{kg}$ in DMSO. The precise dose administered to each ewe was determined by weighing the syringe before and after injection and by measuring the activity of a $10-\mu l$ weighed aliquot of the $\left[{ }^{3} \mathrm{H}\right]$ cortisol solution.

Blood samples were obtained from the left jugular vein with an indwelling catheter inserted the day before the experiments. Blood samples were collected in heparinized tubes and centrifuged for $10 \mathrm{~min}$ at $1,400 \mathrm{~g}$. The plasma was separated and stored at $-20^{\circ} \mathrm{C}$ until assay.

Analytical methods. Cortisol was assayed in duplicate using 50- $\mu$ l aliquots of plasma and the RIA method adapted from Gomez Brunet and Lopez Sebastian (8). The level of quantification of the assay was $2 \mathrm{ng} / \mathrm{ml}$. The mean intraassay coefficient of variation for three plasma levels $(4,16$, and $32 \mathrm{ng} / \mathrm{ml}$ ) was $13 \%$; the mean interassay coefficient of variation for these plasmas was $14 \%$. The cortisol specific activity was measured by coupling HPLC and scintillation liquid counting techniques as previously described (14).

\section{Data Analysis}

In vitro protein binding. Protein-bound cortisol concentrations were plotted against the unbound cortisol concentrations. The profiles indicated the presence of saturable and nonsaturable protein binding, CBG, and albumin. The data were fitted by use of the following relationship

$$
\mathrm{B}=\frac{\mathrm{B}_{\max } \times \mathrm{F}}{K_{\mathrm{d}}+\mathrm{F}}+N S \times \mathrm{F}
$$

where $\mathrm{F}$ and $\mathrm{B}$ are the concentrations of free and bound cortisol, respectively. $\mathrm{B}_{\max }(\mathrm{nM})$ and $K_{\mathrm{d}}(\mathrm{nM})$ are the CBG maximal binding capacity and the cortisol dissociation constant, respectively, i.e., the free plasma cortisol corresponding to half-saturation of CBG. NS is a dimensionless proportionality constant for the nonspecific binding of cortisol to albumin. Binding parameters $\left(\mathrm{B}_{\max }, K_{\mathrm{d}}\right.$, and $\left.N S\right)$ were evaluated by a computerized nonlinear least squares regression program adapted from Multi (23).

\section{Kinetic Analysis}

Experiment 1. The following two approaches were used to analyze the total plasma cortisol concentrations: the statistical moment approach was used to calculate the total plasma cortisol clearance and the compartmental analysis to estimate the plasma clearance of CBG-free cortisol and CBGbinding parameters ( $\left.\mathrm{B}_{\max }, K_{\mathrm{d} \text { CBG-free }}\right)$.

The total plasma cortisol clearance $\left(\mathrm{Cl}_{\mathrm{T}}, \mathrm{ml} \cdot \mathrm{kg}^{-1} \cdot \mathrm{min}^{-1}\right)$ was calculated using $E q .2$

$$
\mathrm{Cl}_{\mathrm{T}}=\text { dose/AUC }
$$

where $\operatorname{AUC}\left(\mathrm{ng} \cdot \mathrm{min} \cdot \mathrm{ml}^{-1}\right)$ is the area under the total plasma cortisol concentration-time curve calculated from time 0 to the last measurable concentration $\left(t_{\text {last }}\right)$ by use of the arithmetic trapezoidal rule, and dose $(\mathrm{ng} / \mathrm{kg})$ is the dose of cortisol administered.

Plasma total cortisol concentrations were also analyzed using a compartmental approach similar to that described previously for inhibitors of angiotensin-converting enzyme (22). A first assumption was that free and albumin-bound cortisol were not distinguishable from a kinetic point of view. These two fractions were therefore pooled and named CBGfree cortisol. CBG-free cortisol was assumed to represent the 
driving force for processes of distribution, elimination, and binding to $\mathrm{CBG}$.

The model of cortisol disposition was therefore described by the following equations

$$
\begin{aligned}
& \mathrm{d} Q_{\mathrm{CBG}-\text { free }} / \mathrm{d} t=- {\left[k_{12}+k_{10}+k_{1} \times\left(A-Q_{\mathrm{CBG}-\text { bound }}\right)\right] } \\
& \times Q_{\mathrm{CBG}-\text { free }}+k_{21} \times Q_{\text {periph }}+k_{2} \times Q_{\mathrm{CBG}-\text { bound }} \\
& \mathrm{d} Q_{\text {periph }} / \mathrm{d} t=k_{12} \times Q_{\mathrm{CBG}-\text { free }}-k_{21} \times Q_{\text {periph }} \\
& \mathrm{d} Q_{\mathrm{CBG} \text {-bound }} / \mathrm{d} t=k_{1} \times\left(A-Q_{\mathrm{CBG}-\text { bound }}\right) \times Q_{\mathrm{CBG}-\text { free }} \\
&-k_{2} \times Q_{\mathrm{CBG}-\text { bound }}
\end{aligned}
$$

where $t$ is time, $Q_{\mathrm{CBG}}$-free is the amount of cortisol not bound to $\mathrm{CBG}$ in the central compartment, $Q_{\text {periph }}$ is the amount of cortisol in the peripheral compartment, $Q_{\mathrm{CBG} \text {-bound }}$ is the amount of cortisol bound to CBG in the central compartment, $A$ is the maximal amount of CBG-binding sites in the central compartment, $k_{1}$ is the second-order rate constant of association of the cortisol-CBG complex, $k_{2}$ is the first-order rate constant of dissociation of the cortisol-CBG complex, $k_{12}$ is the first-order rate constant of transfer from central to peripheral compartment, $k_{21}$ is the first-order rate constant of transfer from peripheral to central compartment, and $k_{10}$ is the first-order rate constant of elimination from the central compartment.

The second hypothesis of our model was to assume nearinstantaneous equilibrium conditions for cortisol binding to $\mathrm{CBG}$, i.e., $\mathrm{d} Q_{\mathrm{CBG}}$-bound $/ \mathrm{d} t=0$, which is in agreement with data concerning the kinetics of the cortisol-CBG interaction (4). Appendix 1 presents step-by-step rearrangements of $E q$. 3 that can be performed under this assumption. Finally, the model described by Eqs. 3-5 can be reduced to Eq. 4 and Eq. 6

$$
\begin{aligned}
\mathrm{d} Q_{\mathrm{CBG}-\text { free }} / \mathrm{d} t=\left[-\left(k_{12}+k_{10}\right) \times\right. & \left.Q_{\mathrm{CBG}-\text { free }}+k_{21} \times Q_{\text {periph }}\right] / \\
& {\left[1+A \times K /\left(K+Q_{\mathrm{CBG}-\text { free }}\right)^{2}\right] }
\end{aligned}
$$

where $K$ is equal to $k_{2} / k_{1}$ and corresponds to the equilibrium dissociation constant (with dimension of quantity).

Equations 4 and 6 were used for in vivo data analysis and parameter estimation. Finally, the estimated parameters were $k_{10}, k_{12}, k_{21}$ (first-order rate constants expressed in $\left.\min ^{-1}\right), \mathrm{V}_{\mathrm{c}}$ (volume of the central compartment, $1 / \mathrm{kg}$ ), A (nmol), and $K$ (nmol).

A fifth-order Runge-Kutta method with variable step size was used to solve the model numerically. The parameters were obtained using REVOL, a free-derivative Monte Carlo minimizing algorithm (11). The goodness of fit of the described model was assessed using least-square criteria. The data points were weighted using $1 / \hat{y}_{i}^{2}$ with $\hat{y}_{i}$, the $i$ th fitted concentration. An $F$-test was used to select the appropriate number of compartments (1 or 2), and a bicompartmental model was selected (Fig. 1).

In this in vivo cortisol disposition model, parameters for in vivo binding to $\mathrm{CBG}$ were $\mathrm{B}_{\max }(E q .7)$ and $K_{\mathrm{dCBG} \text {-free }}(E q .8)$

$$
\begin{gathered}
\mathrm{B}_{\max }=A / \mathrm{V}_{\mathrm{c}} \\
K_{\mathrm{d} \text { CBG-free }}=k_{2} /\left(k_{1} \times \mathrm{V}_{\mathrm{c}}\right)=K / \mathrm{V}_{\mathrm{c}}
\end{gathered}
$$

Considering that the concentration of cortisol not bound to $\mathrm{CBG}$ is the driving force for the interaction with $\mathrm{CBG}$, the concentration of the cortisol-CBG complex at equilibrium $\left(\mathrm{B}_{\mathrm{CBG}}\right)$ is given by the following equation

$$
\mathrm{B}_{\mathrm{CBG}}=\frac{\mathrm{B}_{\max } \times \mathrm{CBG}_{\text {free }}}{K_{\mathrm{d} \text { CBG-free }}+\mathrm{CBG}_{\text {free }}}
$$

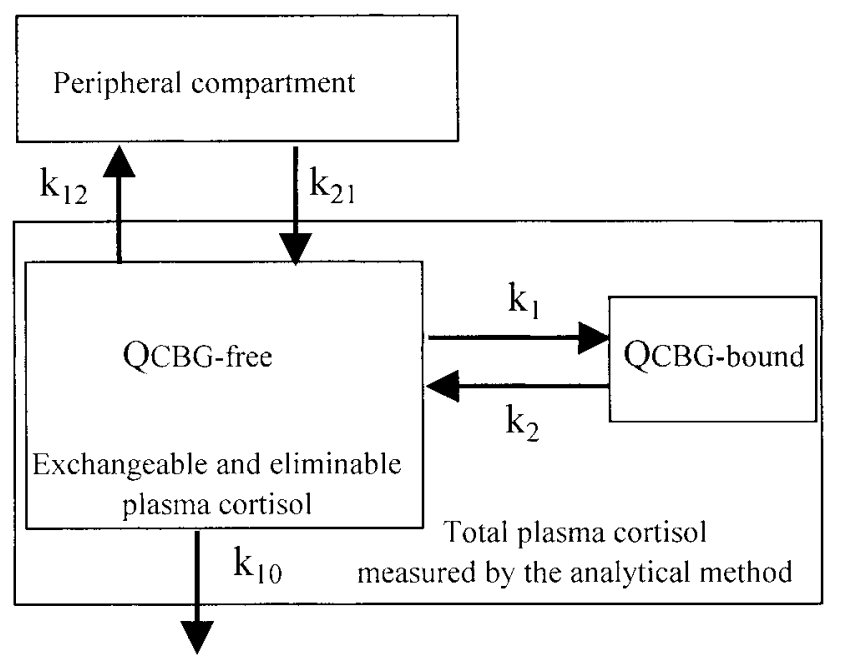

Fig. 1. Physiologically based bicompartmental model for cortisol disposition. The total plasma cortisol amount actually measured by the analytical method is the sum of 1) cortisol specifically and reversibly bound to corticosteroid-binding globulin (CBG; termed $Q_{\mathrm{CBG}-b o u n d}$ ) and 2) cortisol not bound to CBG (termed $Q_{\mathrm{CBG} \text {-free). }}$ $Q_{\mathrm{CBG}-\text { free }}$ represents the fraction eliminated, according to the firstorder rate constant $k_{10}$, and exchanged between the central and peripheral compartments with the first-order rate constants $k_{12}$ and $k_{21}$. $k_{1}$ is the second-order rate constant of association of the cortisolCBG complex; $k_{2}$ is the first-order rate constant of dissociation of the cortisol-CBG complex. On the assumption that equilibrium conditions for cortisol binding to CBG were achieved, the equilibrium dissociation constant [which corresponds to the ratio $k_{2} /\left(k_{1} \times \mathrm{V}_{\mathrm{c}}\right)$, where $V_{c}$ is the volume of the central compartment] and maximal binding $\left(\mathrm{B}_{\max }\right)$ were estimated.

where $\mathrm{CBG}_{\text {free }}$ is the cortisol concentration not bound to $\mathrm{CBG}$ in the central compartment $\left(\mathrm{CBG}_{\text {free }}=Q_{\mathrm{CBG} \text {-free }} / \mathrm{V}_{\mathrm{c}}\right)$. Remenbering that $\mathrm{CBG}_{\text {free }}$ represents free plus albumin-bound cortisol, $\mathrm{CBG}_{\text {free }}$ can be described by the following equation

$$
\mathrm{CBG}_{\text {free }}=\mathrm{F}+N S \times \mathrm{F}=\mathrm{F} \times(N S+1)
$$

Then, substituting from Eq. 10 into Eq. 9 and rearranging gives

$$
\mathrm{B}_{\mathrm{CBG}}=\frac{\mathrm{B}_{\max } \times \mathrm{F}}{\frac{K_{\mathrm{d} \text { CBG-free }}}{(N S+1)}+\mathrm{F}}
$$

When Eqs. 1 and 11 are considered, the following relation can be established

$$
K_{\text {d CBG-free }}=K_{\mathrm{d}} \times(N S+1)
$$

where $K_{\mathrm{d} \text { CBG-free }}$ and $K_{\mathrm{d}}$ refer to $\mathrm{CBG}_{\text {free }}$ and $\mathrm{F}$ as driving concentrations for cortisol-CBG interaction, respectively.

The plasma clearance of $\mathrm{CBG}$-free cortisol $\left(\mathrm{Cl}_{\mathrm{CBG}}\right.$-free; $\mathrm{ml} \cdot \mathrm{kg}^{-1} \cdot \mathrm{min}^{-1}$ ) was calculated from the estimated parameters using Eq. 13

$$
\mathrm{Cl}_{\mathrm{CBG}-\text { free }}=k_{10} \times \mathrm{V}_{\mathrm{c}}
$$

Experiment 2. The kinetic parameters for $\left[{ }^{3} \mathrm{H}\right]$ cortisol were calculated from the plasma cortisol activity concentration [disintegrations $\cdot \min ^{-1}(\mathrm{dpm}) \cdot \mathrm{ml}^{-1}$ ] time profile using a statistical moment approach. The area under the curve (AUC*) was calculated from time 0 to $t_{\text {last }}$ using the arithmetic trapezoidal rule.

The total plasma cortisol clearance $\left(\mathrm{Cl}_{\mathrm{T}}^{*}, \mathrm{ml} \cdot \mathrm{kg}^{-1} \cdot \mathrm{min}^{-1}\right)$ was calculated using $E q .14$ 


$$
\mathrm{Cl}_{\mathrm{T}}^{*}=\text { dose/AUC } *
$$

where $\mathrm{AUC}^{*}\left(\mathrm{dpm} \cdot \mathrm{min} \cdot \mathrm{ml}^{-1}\right)$ is the area under the plasma cortisol activity concentration-time curve, and dose ( $\mathrm{dpm} / \mathrm{kg})$ is the dose of $\left[{ }^{3} \mathrm{H}\right]$ cortisol administered. The corresponding plasma CBG-free cortisol clearance $\left(\mathrm{Cl}_{\mathrm{CBG}}^{*}\right.$-free; $\mathrm{ml} \cdot \mathrm{kg}^{-1}$. $\min ^{-1}$ ) was then computed taking into account the relationships defined by Eqs. 15 and 16. By definition of clearance

$$
\mathrm{Cl}_{\mathrm{T}}^{*}=\frac{\mathrm{d} X^{*} / \mathrm{d} t}{\mathrm{TOT}^{*}}
$$

and

$$
\mathrm{Cl}_{\mathrm{CBG}-\text { free }}^{*}=\frac{\mathrm{d} X^{*} / \mathrm{d} t}{\mathrm{CBG}_{\text {free }}^{*}}
$$

where $\mathrm{d} X^{*} / \mathrm{d} t$ is the overall elimination rate of $\left[{ }^{3} \mathrm{H}\right]$ cortisol, TOT $^{*}$ is the total labeled plasma cortisol concentration, and $\mathrm{CBG}_{\text {free }}^{*}$ is the plasma CBG-free labeled cortisol concentration.

By combining Eqs. 15 and 16

$$
\mathrm{Cl}_{\mathrm{CBG}-\text { free }}^{*}=\mathrm{Cl}_{\mathrm{T}}^{*} \frac{\mathrm{TOT}^{*}}{\mathrm{CBG}_{\text {free }}^{*}}
$$

Because dexamethasone was injected $3 \mathrm{~h}$ before radiolabeled cortisol, in this experiment there was no endogenous (cold) cortisol, and $\mathrm{TOT}^{*}$ is given by the general relationship (Eq. 18)

$$
\mathrm{TOT}^{*}=\mathrm{F}^{*}+\frac{\mathrm{B}_{\max } \mathrm{F}^{*}}{K_{\mathrm{d}}+\mathrm{F}^{*}}+N S \times \mathrm{F}^{*}
$$

where $\mathrm{F}^{*}$ is the free labeled cortisol. Taking into account that in our experimental conditions $K_{\mathrm{d}}>>\mathrm{F}^{*}$ and after rearranging Eq. 18, we then obtained Eq. 19

$$
\mathrm{TOT}^{*}=\mathrm{F}^{*}(N S+1)+\frac{\mathrm{B}_{\max } \mathrm{F}^{*}}{K_{\mathrm{d}}}
$$

Equation 19 can be rewritten as Eq. 20

$$
\mathrm{TOT}^{*}=\mathrm{F}^{*}(N S+1)+\frac{\mathrm{B}_{\max } \mathrm{F}^{*}(N S+1)}{K_{\mathrm{d}}(N S+1)}
$$

By definition, $\mathrm{F}^{*}(N S+1)$ is the plasma $\mathrm{CBG}_{\text {free }}^{*}$ cortisol concentration. Thus Eq. 20 can be written as Eq. 21

$$
\mathrm{TOT}^{*}=\mathrm{CBG}_{\text {free }}^{*}\left(1+\frac{\mathrm{B}_{\max }}{K_{\mathrm{d}}(N S+1)}\right)
$$

Inspection of $E q .21$ indicates that the $\mathrm{TOT}^{*}$-to-CBG $\mathrm{CB}_{\text {free }}^{*}$ ratio is a constant; thus, $E q .17$ can be expressed by $E q .22$

$$
\mathrm{Cl}_{\mathrm{CBG}-\text { free }}^{*}=\mathrm{Cl}_{\mathrm{T}}^{*}\left[\frac{K_{\mathrm{d}}(N S+1)+\mathrm{B}_{\text {max }}}{K_{\mathrm{d}}(N S+1)}\right]
$$

where $\mathrm{Cl}_{\mathrm{T}}^{*}$ is obtained from $E q .14$, and $\mathrm{B}_{\max }, K_{\mathrm{d}}$, and $N S$ are determined by in vitro binding experiments. $\mathrm{Cl}_{\mathrm{CBG}}^{*}$-free calculated from $E q$. 22 , i.e., by a noncompartmental analysis, can be compared with that obtained by modeling total plasma cortisol concentrations (see Eq. 13).

Experiment 3. The entry rate of cortisol (ER, $\mathrm{mg} / \mathrm{h}$ ) was calculated for each ewe by use of $E q .23$

$$
\mathrm{ER}=\mathrm{AUC}_{\mathrm{CBG} \text {-free }} \times \mathrm{Cl}_{\mathrm{CBG} \text {-free }}
$$

in which $\mathrm{Cl}_{\mathrm{CBG}-\text { free }}$ values were obtained for the three cortisol doses determined using the modeling approach (experiment 1 ), and $\mathrm{AUC}_{\mathrm{CBG} \text {-free }}$ is the area under the steady-state plasma CBG-free concentration-time curve calculated using the arithmetic trapezoidal rule from $t=100$ to $t=260 \mathrm{~min}$ for the first period and from $t=40$ to $t=220 \mathrm{~min}$ after the beginning of each perfusion for the second period. $\mathrm{CBG}_{\text {free }}$ were calculated from $E q .24$, adapted from Tait and Burstein (21)

$$
\begin{aligned}
\mathrm{CBG}_{\text {free }}= & 0.5 \times\left[\left(\mathrm{TOT}-\mathrm{B}_{\max }-K_{\mathrm{d} \text { CBG-free }}\right)+\right. \\
& \sqrt{\left.\left(K_{\mathrm{d} \text { CBG-free }}-\mathrm{TOT}+\mathrm{B}_{\max }\right)^{2}+4 \times \text { TOT } \times K_{\mathrm{d} \text { CBG-free }}\right]}
\end{aligned}
$$

where TOT is the measured total plasma cortisol concentration, and $\mathrm{B}_{\max }$ and $K_{\mathrm{d}}$ CBG-free are the individual means of CBG-binding parameter values obtained for the three cortisol doses with the modeling approach (experiment 1 ).

Statistical analysis. The results are reported as means \pm SD. The Systat 8.0 Statistics program (SPSS, Chicago, IL) was used for statistical analysis. A $P$ value $<0.05$ was considered significant. Plasma cortisol concentrations below the limit of quantification of the assay were arbitrarily fixed at 1 $\mathrm{ng} / \mathrm{ml}$. CBG-binding parameters and total and CBG-free cortisol kinetic parameters obtained 1) after different cortisol doses given at 1-wk intervals according to a crossover design using a modeling approach (experiment 1) and 2) by the reference radioisotopic method or equilibrium dialysis (experiment 2) were compared using an ANOVA for repeated measurement design including one factor (dose) followed by a Dunnett's two-sided test. The nonparametric Wilcoxon test was used to compare the cortisol entry rates calculated from plasma CBG-free cortisol clearance and CBG-binding parameters obtained with the modeling approach with corresponding real cortisol perfusion rates.

\section{RESULTS}

In all experiments, the plasma cortisol concentrations obtained $3 \mathrm{~h}$ after a $0.1 \mathrm{mg} / \mathrm{kg}$ intravenous dexamethasone administration were below the level of quantification of the assay in all ewes, i.e., $2 \mathrm{ng} / \mathrm{ml}$.

\section{In Vivo Radiolabeled Cortisol Disposition and In Vitro Binding Experiments}

Figure 2 shows the time course of $\left[{ }^{3} \mathrm{H}\right]$ cortisol activity concentration in six ewes after an intravenous administration of $5 \mu \mathrm{Ci} / \mathrm{kg}\left[{ }^{3} \mathrm{H}\right]$ cortisol. Figure 3 shows the observed and fitted concentrations of cortisol bound

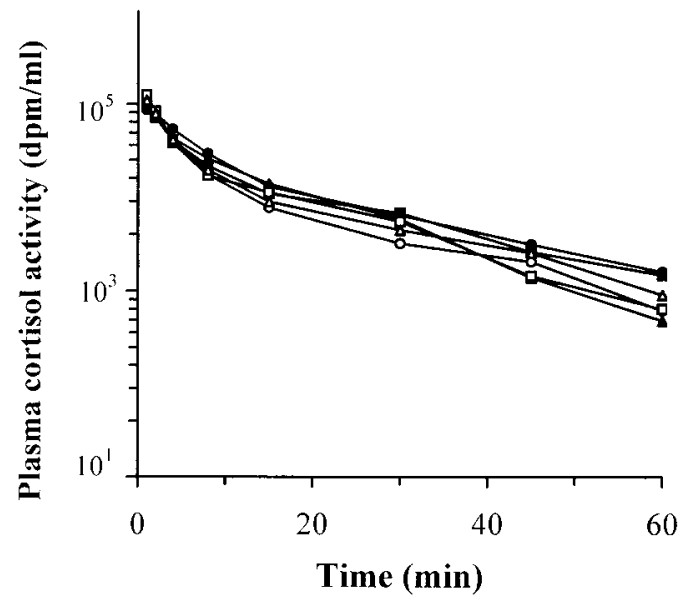

Fig. 2. Semilogarithmic plot of $\left[{ }^{3} \mathrm{H}\right]$ cortisol activity concentration vs. time in 6 ewes after administration of $5 \mu \mathrm{Ci} / \mathrm{kg}\left[{ }^{3} \mathrm{H}\right]$ cortisol. 


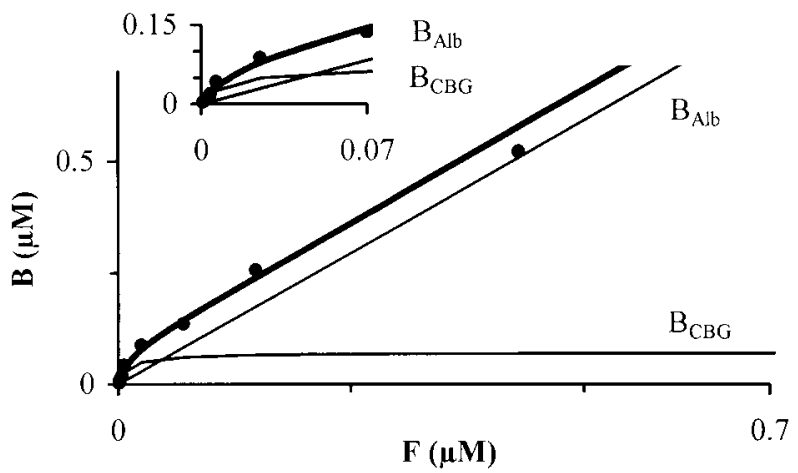

Fig. 3. Plasma protein-bound (B) concentrations as a function of free cortisol concentrations obtained by equilibrium dialysis for a representative ewe (•) and fitting of protein-bound (B, thick line), CBGbound $\left(\mathrm{B}_{\mathrm{CBG}}\right.$, thin line), and albumin-bound ( $\mathrm{B}_{\mathrm{Alb}}$, thin line) cortisol obtained from $E q .1$ by a computerized nonlinear least squares regression program. Inset: the shape of fitted curves for low free cortisol concentrations.

to plasma proteins as a function of free cortisol concentrations, obtained by equilibrium dialysis, for a representative ewe. Mean total and CBG-free cortisol kinetics and CBG-binding parameters obtained from the plasma activity and equilibrium dialysis are given in Table 1.

The mean plasma total cortisol clearance, obtained by using the trapezoidal rule, was $11 \pm 1 \mathrm{ml} \cdot \mathrm{kg}^{-1} \cdot \mathrm{min}^{-1}$. The mean values of $\mathrm{B}_{\max }, K_{\mathrm{d}}$, and $N S$ evaluated by in vitro equilibrium dialysis were $69 \pm 13 \mathrm{nM}(25 \pm 5$ $\mathrm{ng} / \mathrm{ml}), 9.6 \pm 1.9 \mathrm{nM}(3.5 \pm 0.7 \mathrm{ng} / \mathrm{ml})$, and $1.1 \pm 0.3$,

Table 1. Pharmacokinetic parameters

\begin{tabular}{lcccc}
\hline \hline & \multicolumn{3}{c}{ Dose, $\mathrm{mg} / \mathrm{kg}$} & \\
\cline { 2 - 4 } \multicolumn{1}{c}{ Parameters } & 0.05 & 0.2 & 1 & Reference \\
\hline $\mathrm{V}_{\mathrm{c}}, \mathrm{ml} / \mathrm{kg}$ & $210 \pm 53$ & $335 \pm 99$ & $259 \pm 82$ & $\mathrm{NA}$ \\
$\mathrm{Cl}_{\mathrm{T}}, \mathrm{ml} \cdot \mathrm{kg}^{-1} \cdot \mathrm{min}^{-1}$ & $26 \pm 5$ & $33 \pm 7$ & $31 \pm 8$ & $11.1 \pm 1$ \\
$\mathrm{Cl}_{\mathrm{CBG}-\mathrm{free}}$ & & & & \\
$\quad \mathrm{ml} \cdot \mathrm{kg}^{-1} \cdot \mathrm{min}^{-1}$ & $48 \pm 9$ & $58 \pm 12$ & $39 \pm 12$ & $54 \pm 16$ \\
$\mathrm{~B}_{\mathrm{max}}, \mathrm{nM}$ & $54 \pm 9$ & $92 \pm 44$ & $95 \pm 43$ & $69 \pm 13$ \\
$K_{\mathrm{d} \text { CBG-free, }} \mathrm{nM}$ & $23.8 \pm 5.3$ & $13.6 \pm 6.2$ & $9.8 \pm 5.9^{*}$ & $20.1 \pm 5.3$
\end{tabular}

Values are means $\pm \mathrm{SD} . \mathrm{V}_{\mathrm{c}}$, volume of the central compartment of the corticosteroid-binding globulin $(\mathrm{CBG})$-free cortisol; $\mathrm{Cl}_{\mathrm{T}}$, plasma

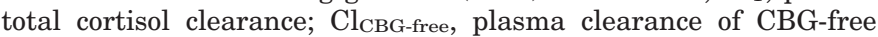
cortisol, i.e., actually free and nonspecifically bound to albumin; $\mathrm{B}_{\max }, \mathrm{CBG}$ maximal binding capacity; $K_{\mathrm{d}}$ CBG-free, dissociation constant $\left(K_{\mathrm{d}}\right)$ of CBG-free cortisol. Shown are pharmacokinetic parameters describing the total and CBG-free cortisol kinetic and CBGbinding parameters after intravenous administration of cortisol at the doses of $0.05,0.2$, and $1 \mathrm{mg} / \mathrm{kg}$ and obtained by modeling total plasma cortisol disposition in 9 ewes and corresponding reference values for total and CBG-free plasma cortisol clearance and CBGbinding parameters evaluated after an intravenous administration of $\left[{ }^{3} \mathrm{H}\right]$ cortisol $(5 \mu \mathrm{Ci} / \mathrm{kg})$ and equilibrium dialysis. The reference values for total, CBG-free plasma cortisol clearance and CBG-binding parameters $\left(\mathrm{B}_{\max }, K_{\mathrm{d}}\right.$ CBG-free $)$ were obtained by a radioisotopic method in 6 ewes and equilibrium dialysis in 9 ewes (experiment 2 ). Reference $K_{\mathrm{d}}$ CBG-free values were estimated by multiplying the individual in vitro $K_{\mathrm{d}}$ values by corresponding calculated $(N S+1)$ values, where $N S$ is a dimensionless proportionality constant for the nonspecific binding of cortisol to albumin. For $\mathrm{Cl}_{\mathrm{CBG} \text {-free, }} \mathrm{B}_{\max }$, and $K_{\mathrm{d} \text { CBG-free }}$ the mean values that have a superscript are significantly different from reference values ( ${ }^{*} P<0.05$ : Dunnett's test). NA, not applicable. respectively. From the individual in vitro CBG-binding parameters $(E q .1)$ and in vivo plasma activity (Eq. 14), the individual values of what we considered to be the reference values of plasma CBG-free cortisol clearance were computed using Eq. $22\left(53.9 \pm 15.7 \mathrm{ml} \cdot \mathrm{kg}^{-1}\right.$. $\left.\min ^{-1}\right)$.

\section{In Vivo Total Plasma Cortisol Modeling}

The semilogarithmic plot for observed total plasma cortisol concentrations and fitted total and CBG-free plasma cortisol concentrations vs. time after intravenous administration of cortisol at three level doses $(0.05,0.2$, and $1 \mathrm{mg} / \mathrm{kg})$ is shown in Fig. 4 for a representative ewe. The data were well fitted to the equation corresponding to a bicompartmental model and including the nonlinear binding to CBG. The estimations of the parameters, i.e., $A, K, \mathrm{~V}_{\mathrm{c}}, k_{10}, k_{12}$, and $k_{21}$, and their precisions are given in Table 2.

Figure 5 shows the interindividual variations of total, CBG-free plasma cortisol clearance, and CBGbinding parameters obtained after the $0.05,0.2$, and 1 $\mathrm{mg} / \mathrm{kg}$ intravenous cortisol administrations (experiment 1) and corresponding reference values evaluated by a radioisotopic method and equilibrium dialysis, respectively (experiment 2 ). The mean total and CBGfree cortisol kinetic parameters and mean CBG-binding parameters obtained after administration of these three doses are given in Table 1.
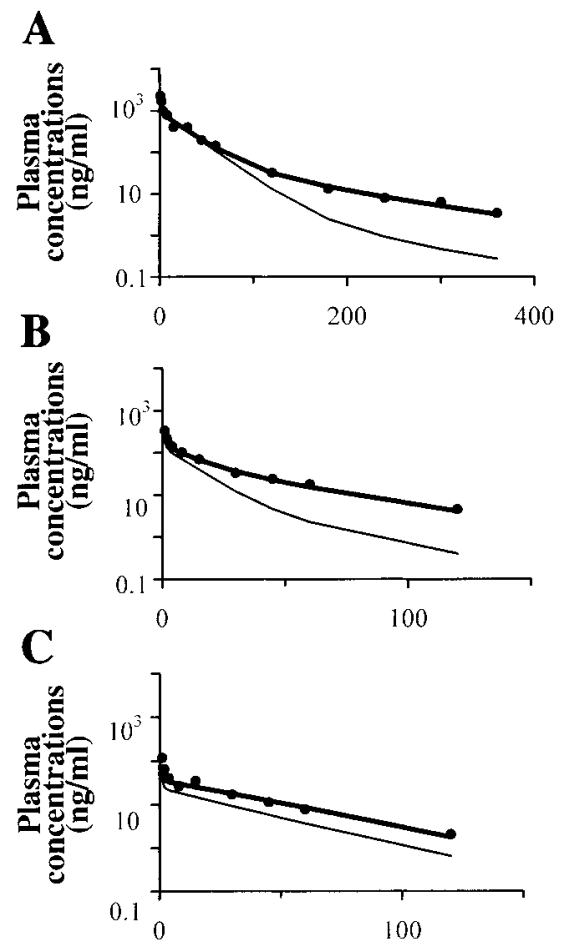

Time (min)

Fig. 4. Semilogarithmic plot for observed total plasma cortisol concentrations (•) and fitted (thick line) total and simulated CBG-free (thin line) plasma cortisol concentrations vs. time after iv administration of cortisol at 3 dose levels [1 $(A), 0.2(B)$, and $0.05 \mathrm{mg} / \mathrm{kg}(C)]$ in a representative ewe. Simulated CBG-free plasma cortisol concentrations were obtained using $E q .24$. 
Table 2. Estimated parameters of the pharmacokinetic model describing the in vivo disposition of CBG-free cortisol, after the intravenous administration of cortisol at the dose of $1 \mathrm{mg} / \mathrm{kg}$

\begin{tabular}{cccr}
\hline $\begin{array}{c}\text { Model } \\
\text { Parameters }\end{array}$ & Estimate & SD & \multicolumn{1}{c}{ CV, \% } \\
\hline$A$ & $19.67-66.27$ & $9.02-72.57$ & $30.1-109.5$ \\
$K$ & $1.500-8.097$ & $0.830-5.111$ & $44.5-101.4$ \\
$\mathrm{~V}_{\mathrm{c}}$ & $0.093-0.372$ & $0.019-0.095$ & $8.8-33.2$ \\
$k_{10}$ & $0.103-0.282$ & $0.026-0.061$ & $18.6-34.1$ \\
$k_{12}$ & $0.115-0.296$ & $0.047-0.184$ & $22.5-65.3$ \\
$k_{21}$ & $0.062-0.179$ & $0.014-0.069$ & $22.5-53.6$ \\
\hline
\end{tabular}

Data presented are the ranges of individual values obtained with 9 ewes. SD, standard deviation; CV, coefficient of variation; $A$, maximal amount of CBG-binding sites in central compartment; $K$, value resulting from dividing first-order rate constant by secondorder rate constant; $k_{10}$, first-order rate constant of elimination from the central compartment; $k_{12}$, first-order rate constant of transfer from the central to peripheral compartment; $k_{21}$, first-order rate constant of transfer from the peripheral to central compartment.

The mean plasma CBG-free cortisol clearance evaluated by modeling the disposition of exogenous cortisol concentrations obtained after cortisol administration at different doses $\left(48 \pm 9,58 \pm 12\right.$, and $39 \pm 12 \mathrm{ml} \cdot \mathrm{kg}^{-1}$. $\mathrm{min}^{-1}$ for $0.05,0.2$, and $1 \mathrm{mg} / \mathrm{kg}$ doses, respectively) did not differ significantly from the control value obtained by the radioisotopic method $\left(54 \pm 16 \mathrm{ml} \cdot \mathrm{kg}^{-1} \cdot \mathrm{min}^{-1}\right.$, Dun- nett's test, $P>0.05$ ). Similarly, the mean $\mathrm{B}_{\max }$ values obtained by the modeling approach for the three cortisol levels ( $54 \pm 9,92 \pm 44$, and $95 \pm 43 \mathrm{nM}$ for $0.05,0.2$, and $1 \mathrm{mg} / \mathrm{kg}$ doses, respectively) did not differ significantly from the mean values obtained by equilibrium dialysis $(69 \pm 13 \mathrm{nM}$, Dunnett's test, $P>0.05)$.

$K_{\mathrm{d}}$ values equivalent to those evaluated by the modeling approach (i.e., $K_{\mathrm{d} \text { CBG-free }}$ ) can be estimated by multiplying the individual in vitro $K_{\mathrm{d}}$ values [9.6 \pm 1.9 $\mathrm{nM}$, mean in vitro $K_{\mathrm{d}}\left(K_{\mathrm{d} \text { in vitro }}\right)$ value, experiment 2 ] by the corresponding calculated $N S+1$ values [ $2.1 \pm 0.3$, mean $(N S+1)$ value]. The mean $K_{\mathrm{d}}$ CBG-free obtained by the modeling approach $(23.8 \pm 5.3$ and $13.6 \pm 6.2$ $\mathrm{nM}$ for 0.05 and $0.2 \mathrm{mg} / \mathrm{kg}$ doses) were not different from the mean apparent $K_{\mathrm{d}}$ values evaluated by equilibrium dialysis $(20.1 \pm 5.3 \mathrm{nM}$, experiment 2 , Dunnett's test, $P>0.05$ ), whereas the mean $K_{\mathrm{d} \text { CBG-free }}$ obtained by the modeling approach for the $1 \mathrm{mg} / \mathrm{kg}$ dose $(9.8 \pm 5.9 \mathrm{nM})$ was significantly lower than the mean apparent $K_{\mathrm{d}}$ value evaluated by equilibrium dialysis (Dunnett's test, $P=0.005$ )

The individual mean values for plasma CBG-free cortisol clearance and CBG-binding parameters obtained after administration of cortisol at three dose levels were used in the following experiments to calculate and compare cortisol entry rates with known corticoid perfusion rates (experiment 3 ).
A
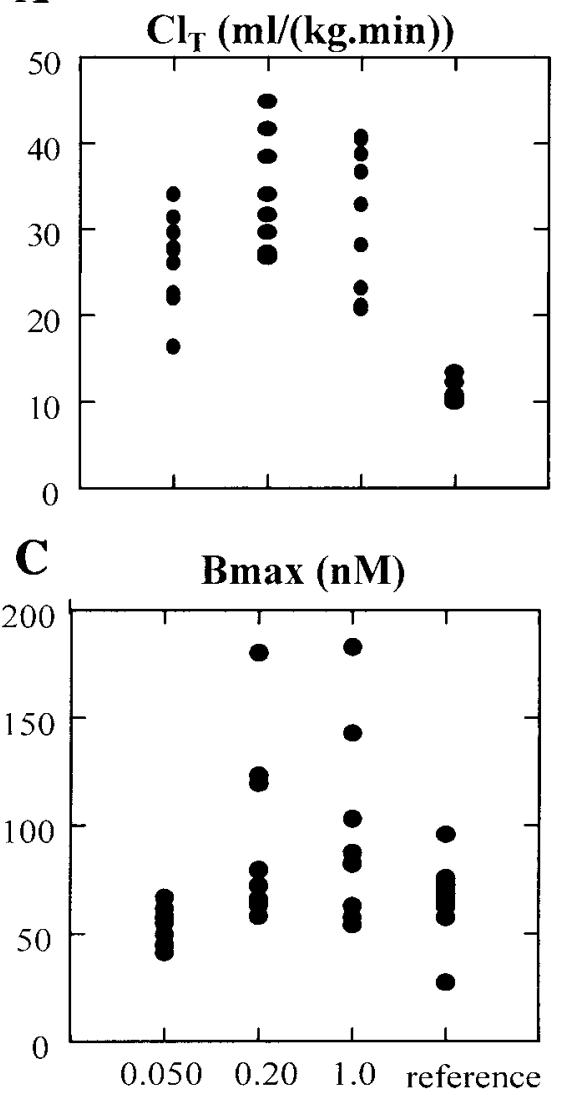

Dose $(\mathbf{m g} / \mathbf{k g})$
B

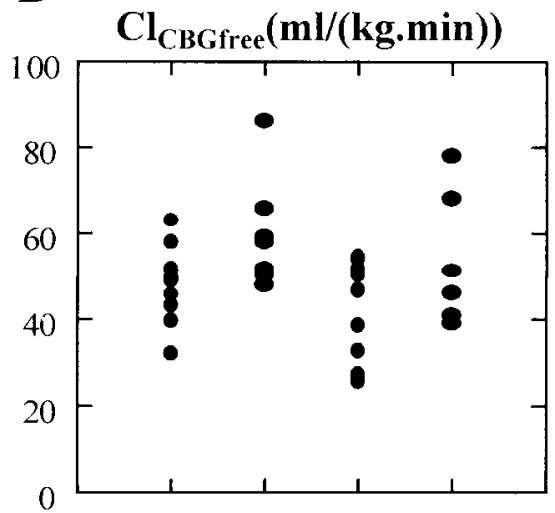

D

Kd (nM)

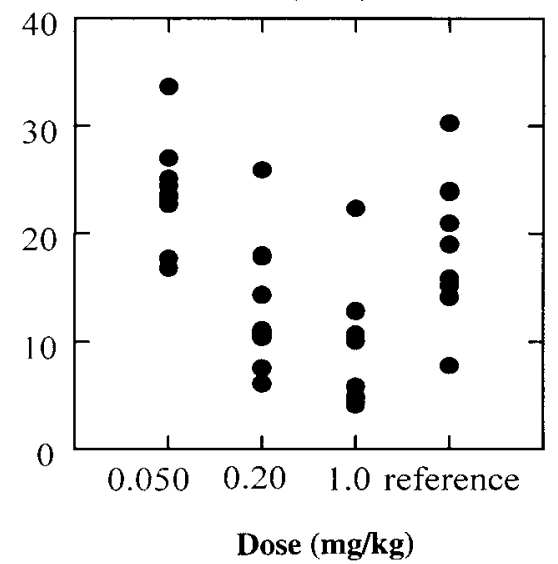

Fig. 5. Interindividual variations of total, CBGfree plasma cortisol clearance, and CBG-binding parameters [maximal binding capacity $\left(\mathrm{B}_{\max }\right)$ and dissociation constant $\left(K_{\mathrm{d}}\right)$ ] estimated by modeling the kinetics of total plasma cortisol concentrations obtained after the intravenous administration of cortisol at 3 dose levels $(0.05,0.2$, and $1 \mathrm{mg} / \mathrm{kg})$ and corresponding reference values evaluated by a radioisotopic method and equilibrium dialysis, respectively. $\mathrm{Cl}_{\mathrm{T}}$, total clearance; $\mathrm{Cl}_{\mathrm{CBG} \text {-free, }}$ clearance of CBG-free cortisol. 
Fig. 6. Total and CBG-free plasma cortisol concentration $(\mathrm{ng} / \mathrm{ml})$ obtained in 6 ewes (thin line) and predictive values (thick line) during the perfusion of cortisol at different rates $(0.27,1.6,2.7,12$, and $18 \mathrm{mg} / \mathrm{h}$ ). The predictive total and CBG-free plasma cortisol concentrations were calculated from the mean cortisol kinetic and CBG-binding parameters estimated by using our modeling approach.

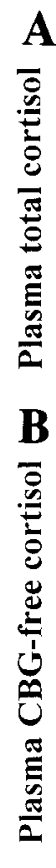

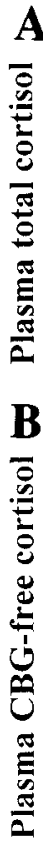
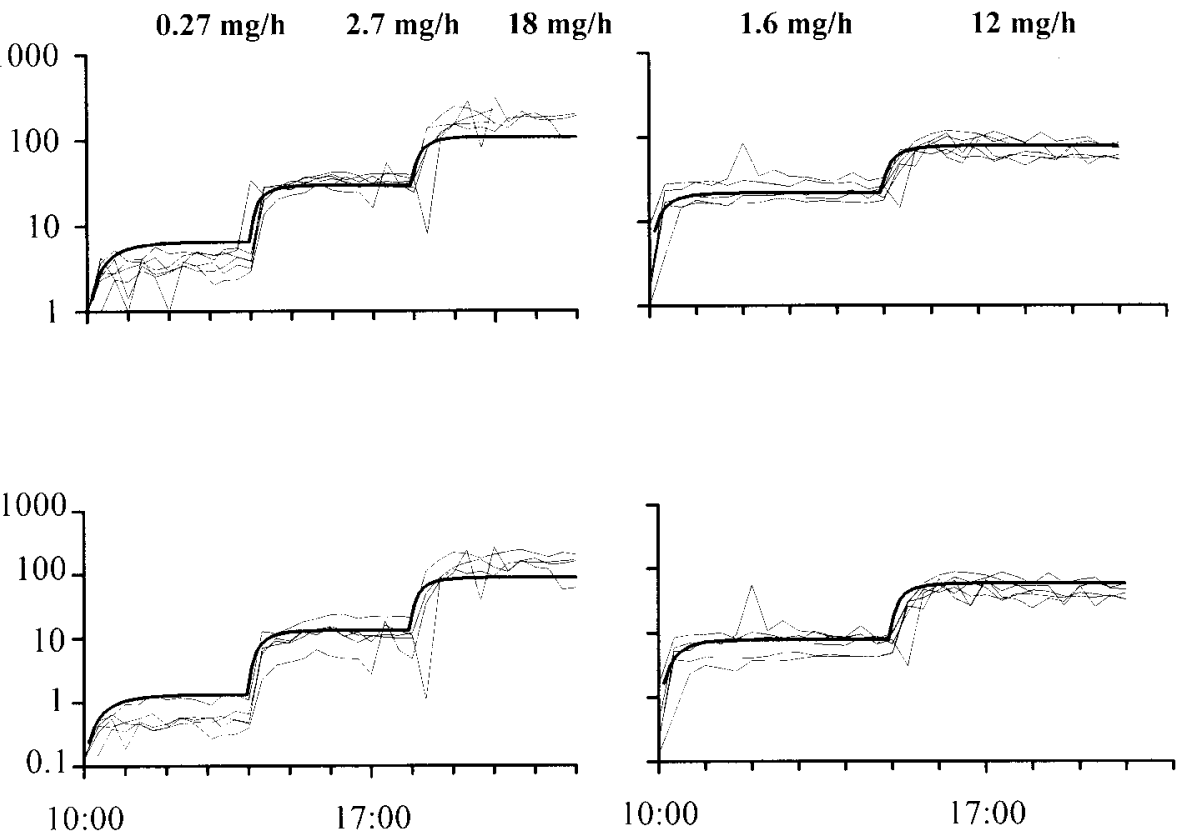

Time of day

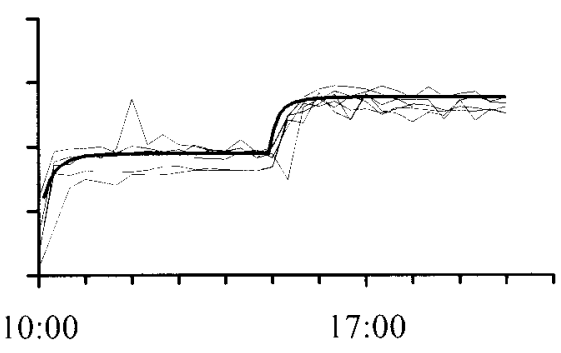

Time of day

\section{Validation of the Method of Estimation of Cortisol Production Rate}

Figure 6 shows the individual plasma total and CBG-free cortisol concentration profile in six ewes and predictive values obtained during the perfusion of corticoid at different rates $(0.27,1.6,2.7,12$, and $18 \mathrm{mg} / \mathrm{h})$. For each perfusion level, an individual cortisol entry rate was calculated from the kinetic and CBG-binding parameters estimated by the modeling approach (experiment 1). Figure 7 shows the mean cortisol entry rates calculated using our modeling approach and the corresponding mean actual corticoid perfusion rates. The calculated entry rates of cortisol were not different from the actual perfusion rates (Wilcoxon test, $P>$ 0.05).

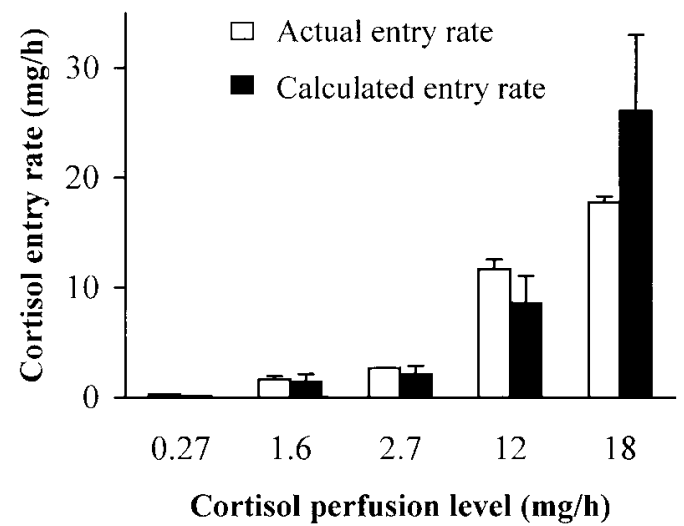

Fig. 7. Mean cortisol entry rates calculated in 6 ewes using the cortisol kinetic and CBG-binding parameters estimated by using our modeling approach and corresponding mean actual cortisol entry rates during the perfusion of cortisol at different rates $(0.27,1.6,2.7$, 12 , and $18 \mathrm{mg} / \mathrm{h}$ ).

\section{DISCUSSION}

Our modeling approach to total plasma cortisol kinetics after the suppression of endogenous cortisol secretion by dexamethasone, which takes into account the specific binding of cortisol to CBG, enabled us to estimate the plasma CBG-free cortisol clearance and CBG-binding parameters $\left(\mathrm{B}_{\max }, K_{\mathrm{d}} \mathrm{CBG}\right.$-free $)$ simultaneously. We have demonstrated that these parameters were reasonably well estimated by comparing them with those obtained by conventional methods, i.e., in vitro equilibrium dialysis for $\mathrm{B}_{\max }$ and $K_{\mathrm{d}}$ in vitro $\times$ $(N S+1)$ and tracer cortisol kinetics for CBG-free cortisol clearance. We have also shown that the same parameters estimated in vivo could be used to determine a cortisol entry rate by mimicking adrenal cortisol secretion with different rates of intravenous cortisol perfusion.

Plasma cortisol kinetics have already been investigated in ewes by means of a constant infusion of $\left[{ }^{3} \mathrm{H}\right]$ cortisol $(9,16-18,20)$; the reported range of clearance values extended from 13.5 to $25 \mathrm{ml} \cdot \mathrm{kg}^{-1} \cdot \mathrm{min}^{-1}$. Such high variability is to be expected, since the clearance calculated from a tracer kinetic study is a total plasma cortisol clearance (i.e., a variable and not a parameter) that fluctuates permanently with the pulsatility of cortisol secretion. Indeed, it is generally admitted that steroid hormones enter cells exclusively via the pool of free hormone (15). Consequently, only the free plasma cortisol can be cleared from the plasma. In physiological conditions, the free plasma cortisol concentrations are of the same order of magnitude as the $K_{\mathrm{d}}$ of cortisol to CBG (10 nM), and the binding of cortisol to CBG is a nonlinear (saturable) process. This means that the relationship between 
total plasma cortisol and CBG-free cortisol is nonlinear within the physiological range of cortisol concentrations; hence, the total cortisol clearance is nonlinear with respect to the physiological plasma cortisol concentrations. This is no longer the case when the plasma cortisol becomes very low (as in our tracer experiment) or very high (as just after our intravenous cortisol administration).

Determination of a cortisol production rate using a plasma clearance approach requires determination of the plasma cortisol clearance, which is a parameter and not a variable. The plasma CBG-free clearance corresponds to this putative clearance, and the ultimate goal of the present experiment was to show that the CBG-free clearance can easily be estimated using an in vivo modeling approach and is not subjected to any dose dependency (i.e., nonlinearity of an origin other than cortisol binding to CBG).

To estimate the CBG-free clearance, we used the modeling approach used for inhibitors of angiotensinconverting enzyme (22), with these drugs binding specifically and saturably to circulating converting enzymes in the same way that cortisol binds to CBG.

For a newly developed model, the first question faced is its identifiability. A model is identifiable when it is able to give a unique value of the parameters when an infinite number of observations is available. We performed several fittings of the individual concentrationtime curves with different initial values of the parameters, and we obtained in all cases the same individual parameter estimations. Moreover, the model was fitted to error-free data simulated with several sets of parameter values and provided unique solutions corresponding to these parameter values. This ability of a model to give a unique solution with a finite number of observations is generally considered an indication that the model is identifiable. The formal proof of identifiability is a complicated mathematical undertaking, especially for nonlinear models, which was in our opinion beyond the scope of this paper.

On the basis of this physiologically based model, the interpretation of the triphasic cortisol disposition after cortisol intravenous administration differs from that involving a classical open tricompartmental model. Indeed, if the initial phase of cortisol disposition also describes a distributional process to a peripheral compartment, the second phase reflects the clearance of CBG-free cortisol, and the terminal phase is related to the release of cortisol from CBG-binding sites. Another particularity of this model is that the steady-state volume of distribution and plasma half-life of CBG-free cortisol are not parameters but variables, and that is why they were not reported here. In other words, the binding-dependent nonlinearity of the model influences the value of the volume of distribution of CBGfree cortisol.

On the other hand, the plasma CBG-free cortisol clearance is structurally independent of CBG binding, but there was no guarantee that the actual CBG-free clearance was a concentration-independent parameter. Indeed, mechanisms other than binding to CBG can be the cause of nonlinearity. The present study showed the independence of plasma CBG-free cortisol concentrations, thus suggesting that clearance of the cortisol not specifically bound to CBG is a parameter able to characterize cortisol disposition, whatever the total plasma cortisol concentration. In other words, within the range of doses tested $(0.05-1 \mathrm{mg} / \mathrm{kg})$, there was no evidence of saturability of plasma CBG-free cortisol clearance (i.e., of cortisol metabolism), thus indicating the very high intrinsic capacity of the clearing process for cortisol.

The plasma clearance of CBG-free cortisol was $\sim 45$ $\mathrm{ml} \cdot \mathrm{kg}^{-1} \cdot \mathrm{min}^{-1}$, i.e., rather high. Considering the hepatic $\left(32 \mathrm{ml} \cdot \mathrm{kg}^{-1} \cdot \mathrm{min}^{-1}\right)$ and kidney $\left(12-17 \mathrm{ml} \cdot \mathrm{kg}^{-1}\right.$. $\min ^{-1}$ ) blood flow rates in the ewe (16), it can be suggested that cortisol is an efficiently cleared analyte and that CBG-free cortisol elimination is rate limited by the liver and kidney blood perfusion rates. This was probably the cause of the relatively high interoccasion variability observed between the means of the plasma free cortisol clearance. In contrast to the plasma clearance of CBG-free cortisol, that of total cortisol depends on cortisol binding to CBG, thus supporting the view that CBG binding protects cortisol from a liver (or kidney) first-pass effect.

Our physiologically based model for total cortisol disposition also enabled the CBG-binding capacity and CBG affinity for cortisol to be determined in vivo. The $K_{\mathrm{d} \text { CBG-free was }} 16 \mathrm{nM}$. In our model, the nonspecific binding of cortisol to albumin was ignored; if the NS parameter was included, we were faced with a problem of structural identifiability for three of the estimated parameters, i.e., $k_{10}, K_{\mathrm{d}}$, and NS. This nonidentifiability was indicated by the fact that a model including a nonspecific binding parameter (i.e., $N S$ ) did not have any effect on the fitting of data simulated without NS. This could be because cortisol displays a gradient of affinity, ranging from low affinity for albumin, intermediate affinity for the enzymatic or clearing transport system, and high affinity for CBG, which could explain why, when the clearance process is under investigation, the free and albumin-bound cortisol behave identically and are both subject to hepatic (and kidney) elimination.

The accuracy of the plasma CBG-free cortisol clearance determined by our modeling approach was supported by two lines of evidence resulting from our tracer experiment and from the computation of plasma total cortisol clearance after administration of a large intravenous cortisol dose. When the plasma cortisol concentrations became very high (with respect to $\left.K_{\mathrm{d} \text { CBG-free }}\right)$, the cortisol disposition became linear because of the total saturation of CBG. Thus, during most of the cortisol disposition after a large cortisol dose, the total plasma cortisol clearance can be considered equal to the plasma CBG-free cortisol clearance. This was the case in our experiment in which the total plasma cortisol clearance $\left(31 \mathrm{ml} \cdot \mathrm{kg}^{-1} \cdot \mathrm{min}^{-1}\right)$ after a dose of 1 $\mathrm{mg} / \mathrm{kg}$ was not significantly different from the plasma CBG-free cortisol clearance. Because of the linearity of the plasma CBG-free cortisol clearance, it can easily be 
approximated to the plasma total cortisol clearance using a statistical moment (i.e., noncompartmental) approach. It should be kept in mind that a very simple data analysis of this kind cannot be used to determine $\mathrm{B}_{\max }$ and $K_{\mathrm{d}}$, the two other parameters required to estimate a cortisol production rate based on the plasma CBG-free cortisol clearance. However, if $\mathrm{B}_{\max }, K_{\mathrm{d}}$, and $N S$ have been independently determined in vitro, the cortisol production rate can be very simply determined by combining the plasma total cortisol clearance and the CBG-free cortisol concentration profile, which can be computed using in vitro $\mathrm{B}_{\max }, K_{\mathrm{d}}$, and $N S$ (see $E q$. 24).

On the other hand, when the cortisol secretion was totally suppressed by dexamethasone, the kinetic disposition of the radiolabeled cortisol also became linear, because the actual radiolabeled maximal plasma cortisol concentrations were low with respect to $K_{\mathrm{d} \text { CBG-free }}$ $(\sim 1.6 \mathrm{nM})$. The analysis of the radiolabeled cortisol disposition using a statistical moment approach (i.e., without any specified structural cortisol model disposition) could be used to measure a plasma total cortisol clearance, this being the minimal possible value of plasma total cortisol clearance compared with the total clearance obtained after a high cortisol dose, which is its maximal limit. Thus, in the present experiment, the range of plasma clearance of total cortisol varied by a factor of three.

The theoretical relationship between this minimal value of plasma total cortisol clearance and that of plasma CBG-free cortisol clearance was determined (see $E q .22$ ). The measured total plasma clearance was used conjointly with $\mathrm{B}_{\max }, K_{\mathrm{d} \text { in vitro, and } N S \text { obtained }}$ by in vitro dialysis to confirm that the plasma CBGfree clearance obtained from in vivo modeling was comparable to that obtained with tracer kinetics and in vitro dialysis parameters.

It can be seen from Eq. 22 that the relationship between plasma CBG-free cortisol clearance (a parameter) and the plasma clearance of total radiolabeled cortisol (also a parameter here) is only determined by $\mathrm{B}_{\max }, K_{\mathrm{d}}$, and $N S$, which control the free cortisol fraction (fu), with $\mathrm{fu}=K_{\mathrm{d}}(N S+1) /\left[\mathrm{B}_{\max }+K_{\mathrm{d}}(N S+1)\right]$ or fu $=K_{\mathrm{d}}$ CBG-free $\left(\mathrm{B}_{\max }+K_{\mathrm{d} \text { CBG-free }}\right)$; thus, $\mathrm{Cl}_{\mathrm{T}}^{*}=\mathrm{Cl}_{\mathrm{CBG}}^{*}$-free $\times$ fu. In the present experiment, fu $=0.20$, indicating that the minimal possible plasma clearance of total cortisol was $\sim 20 \%$ of that of CBG-free cortisol.

The validity and usefulness of our modeling method for the evaluation of cortisol production rate was tested by determining the cortisol entry rate simulated by constant cortisol infusion in dexamethasone-suppressed ewes from plasma CBG-free cortisol kinetics and from the CBG-binding parameters determined by the in vivo modeling approach. We were thus able to show that these parameters could be used to determine cortisol production rate for a wide range of perfusion levels extending from physiological levels to levels 10 times greater than the CBG maximal binding capacity.

The production rate of cortisol has been investigated extensively in humans $(3,10,12,13)$ and in different species, including horses (14) and ewes $(7,17,18)$, but the results have varied according to the methodological approach used. Stable isotope infusion combined with chromatographic mass spectrometric detection has permitted an accurate determination of cortisol production rate in humans (5). These methods require the application of cumbersome and expensive analytical methods (HPLC/mas spectrometry) that are not always readily available to research laboratories.

The cortisol metabolic clearance method is based on the use of radioisotopic tracers that do not interfere with endogenous cortisol secretion. The production rate is obtained by measuring a series of snapshotspecific cortisol activities that enables accurate evaluation of the cortisol production rate but not computation of a cortisol clearance term, which is a parameter. This clearance term, which can be derived from a tracer trial, is only a local variable that depends on the actual plasma cortisol concentration and cannot be reused for another experiment. In contrast to all of the aforementioned methods, our method of cortisol production rate measurement is simple, easy to perform, accurate, and inexpensive, and it only requires in vivo modeling. Such a method should encourage the use of cortisol production rate rather than total cortisol plasma concentrations to assess the influence of different factors, such as stress, exercise, and disease on adrenal gland function. Indeed, the nonlinear relationship between cortisol production and plasma cortisol concentrations has often led to inadequate conclusions on adrenal secretion when only the plasma total cortisol concentrations are used as end points. Alexander and Irvine (1) showed that social stress altered CBG levels in horses, resulting in an increase of free cortisol concentrations, whereas no effect was detected when only the total cortisol was measured. Exercise in that species was shown to trigger a sixfold increase in the adrenal secretion rate, which was not accurately reflected by the more limited increase $(2-3 \times)$ of plasma cortisol concentrations (14). Our modeling approach recently enabled us to show that the hypercortisolism of scrapie-affected ewes (19) resulted from a large increase in cortisol production rate $(5 \times)$, whereas the plasma total cortisol concentrations were only doubled (7).

In conclusion, we have developed a method of evaluating the cortisol production rate based on modeling of cortisol kinetics after cortisol administration in dexamethasone-suppressed ewes. This method enabled us to simultaneously 1) characterize the capacity of cortisol elimination in this species by a parameter, the CBG-free cortisol clearance, and 2) evaluate the plasma CBG-binding parameters. In most mammal species, the saturable binding of cortisol to CBG greatly contributes to the nonlinear cortisol disposition and accounts for the discrepancy between the cortisol production rate and cortisol plasma concentrations. Hence, our model of cortisol disposition can be extended to these species after an initial validation step to ensure that the binding of cortisol to CBG is the only mechanism that contributes to the nonlinear cortisol disposition. Such a methodological approach could also 
be developed to study the disposition of molecules for which the nonlinear disposition is attributable to their saturable binding to plasma proteins.

\section{APPENDIX}

\section{Cortisol Disposition Model}

The model of cortisol disposition is described by the following equations

$$
\begin{aligned}
& \mathrm{d} Q_{\mathrm{CBG}-\text { free }} / \mathrm{d} t=-\left(k_{12}+k_{10}+k_{1} \times\left[A-Q_{\mathrm{CBG}-\text { bound }}\right)\right] \\
& \times Q_{\mathrm{CBG}-\text { free }}+k_{21} \times Q_{\text {periph }}+k_{2} \times Q_{\mathrm{CBG}-\text { bound }} \\
& \mathrm{d} Q_{\text {periph }} / \mathrm{d} t=k_{12} \times Q_{\mathrm{CBG}-\text { free }}-k_{21} \times Q_{\text {periph }} \\
& \mathrm{d} Q_{\mathrm{CBG}-\text { bound }} / \mathrm{d} t=k_{1} \times\left(A-Q_{\mathrm{CBG}-\text { bound }}\right) \\
& \times Q_{\mathrm{CBG}-\text {-free }}-k_{2} \times Q_{\mathrm{CBG}-\text { bound }}
\end{aligned}
$$

Equation $A 1$ can be written as

$$
\begin{aligned}
\mathrm{d} Q_{\text {CBG-free }} / \mathrm{d} t=-\left(k_{12}+k_{10}\right) \times Q_{\mathrm{CBG}-\text { free }} & +k_{21} \times Q_{\text {periph }} \\
& -\mathrm{d} Q_{\mathrm{CBG} \text {-bound }} / \mathrm{d} t
\end{aligned}
$$

and

$$
\mathrm{d} Q_{\mathrm{CBG}-\text { bound }} / \mathrm{d} t=\left(\mathrm{d} Q_{\mathrm{CBG}-\text { bound }} / \mathrm{d} Q_{\mathrm{CBG}-\text {-reee }}\right) \times\left(\mathrm{d} Q_{\mathrm{CBG}-\text { free }} / \mathrm{d} t\right)
$$

Substituting from Eq. A5 into Eq. A4 and rearranging gives

$$
\begin{array}{r}
\mathrm{d} Q_{\mathrm{CBG}-\text {-rree }} / \mathrm{d} t=\left[-\left(\mathrm{k}_{12}+k_{10}\right) \times Q_{\mathrm{CBG}-\text {-rree }}+k_{21} \times Q_{\text {periph }}\right] / \\
\left(1+\mathrm{d} Q_{\mathrm{CBG}-\text {-bound }} / \mathrm{d} Q_{\mathrm{CBG}-\text {-free }}\right)
\end{array}
$$

Rearrangement of $E q$. A3 now gives

$$
\begin{aligned}
Q_{\mathrm{CBG}-\text { bound }}=\left[k_{1} \times A \times Q_{\mathrm{CBG}-\text { free }}-(\right. & \left.\left.\mathrm{d} Q_{\mathrm{CBG} \text {-bound }} / \mathrm{d} t\right)\right] / \\
& \left(k_{1} \times Q_{\mathrm{CBG}-\text { free }}+k_{2}\right)
\end{aligned}
$$

Dividing the top and bottom of $E q$. $A 7$ by $k_{1}$ gives

$$
\begin{array}{r}
Q_{\mathrm{CBG}-\text { bound }}=\left[A \times Q_{\mathrm{CBG}-\text { free }}-\left(1 / k_{1}\right) \times\left(\mathrm{d} Q_{\mathrm{CBG}-\text { bound }} / \mathrm{d} t\right)\right] / \\
\left(Q_{\mathrm{CBG}-\text {-ree }}+k_{2} / k_{1}\right)
\end{array}
$$

When $k_{1}$ is large, $E q$. $A 8$ reduces to $E q$. $A 9$

$$
Q_{\mathrm{CBG}-b o u n d}=A \times Q_{\mathrm{CBG}-\text { free }} /\left(Q_{\mathrm{CBG}-\text { free }}+K\right)
$$

where $K=k_{2} / k_{1}$.

Equation A9 also results from assuming equilibrium conditions, i.e., $\mathrm{d} Q_{\mathrm{CBG}-\text { bound }} / \mathrm{d} t=0$. Differentiation of $E q . A 9$ with respect to $Q_{\mathrm{CBG}-\text { free }}$ now gives

$$
\mathrm{d} Q_{\mathrm{CBG}-\text { bound }} / \mathrm{d} Q_{\mathrm{CBG}-\text { free }}=A \times K /\left(K+Q_{\mathrm{CBG}-\text { free }}\right)^{2}
$$

and substituting from $E q$. A10 into $E q$. A6 gives

$$
\begin{array}{r}
\mathrm{d} Q_{\text {CBG-free }} / \mathrm{d} t=\left[-\left(\mathrm{k}_{12}+k_{10}\right) \times Q_{\mathrm{CBG}-\text { free }}+k_{21} \times Q_{\text {periph }}\right] / \\
{\left[1+A \times K /\left(K+Q_{\mathrm{CBG}-\text {-free }}\right)^{2}\right]}
\end{array}
$$

Finally, assuming equilibrium conditions for cortisol binding to $\mathrm{CBG}$, the model described by $E q s$. $A 1-A 3$ can be reduced to Eqs. A2 and A11, which were the two working equations used in the present experiment.

For more explanations, see Ref. 22a.

We are grateful to S. Baurès, N. Gautier, and J.F. Sutra for assistance and F. Lyazrhi for critical analysis of the statistics.

\section{REFERENCES}

1. Alexander SL and Irvine CHG. The effect of social stress on adrenal axis activity in horses: the importance of monitoring corticosteroid-binding globulin capacity. J Endocrinol 157: 425$432,1998$.

2. Alvinerie M, Houin G, and Toutain PL. Prednisolone binding to plasma proteins in domestic species. J Pharm Sci 77: 937938, 1988.

3. De Lacerda L, Kowarski A, and Migeon CJ. Diurnal variation of the metabolic clearance rate of cortisol. Effect on measurement of cortisol production rate. J Clin Endocrinol Metab 36: 1043-1049, 1973.

4. Dixon PF. The kinetics of the exchange between transcortinbound and unbound cortisol in plasma. J Endocrinol 40: 457465, 1968.

5. Esteban NV and Yergey AL. Cortisol production rates measured by liquid chromatography/mass spectrometry. Steroids 55 : 152-158, 1990.

6. Gayrard V, Alvinerie M, and Toutain PL. Interspecies variations of corticosteroid-binding globulin parameters. Domest Anim Endocrinol 13: 35-45, 1996.

7. Gayrard V, Picard-Hagen N, Grino M, Sauze N, Grandjean C, Galea J, Andreoletti O, Schelcher F, and Toutain PL. Major hypercorticism is an endocrine feature of ewes with naturally occurring scrapie. Endocrinology 141: 988994, 2000.

8. Gomez Brunet A, and Lopez Sebastian A. Effect of season on plasma concentrations of prolactin and cortisol in pregnant, non-pregnant and lactating ewes. Anim Reprod Sci 26: 251-268, 1991.

9. Hennessy DP, Coghlan JP, Hardy KJ, Scoggins BA, and Wintour EM. The origin of cortisol in the blood of fetal sheep. $J$ Endocrinol 95: 71-79, 1982.

10. Kerrigan JR, Veldhuis JD, Leyo SA, Iranmanesh A, and Rogol AD. Estimation of daily cortisol production and clearance rates in normal pubertal males by deconvolution analysis. J Clin Endocrinol Metab 76: 1505-1510, 1993.

11. Koeppe $\mathbf{P}$ and Hamann C. A program for non-linear regression analysis to be used on desk-top computers. Comput Methods Programs Biomed 12: 121-128, 1980.

12. Kraan GPB and Drayer NM. Cortisol production rate in children by gas chromatography/mass spectrometry using [1,2,3,4$\left.{ }^{13} \mathrm{C}\right]$ cortisol. Steroids 55: 159-164, 1990.

13. Kraan GPB, Dullaart RPF, Pratt JJ, Wolthers BG, Drayer NM, and De Bruin R. The daily cortisol production reinvestigated in healthy men. The serum and urinary cortisol production rates are not significantly different. J Clin Endocrinol Metab 83: $1247-1252,1998$.

14. Lassourd V, Gayrard V, Laroute V, Alvinerie M, Bénard P, Courtot D, and Toutain PL. Cortisol disposition in horses during rest and exercise. Am J Physiol Regulatory Integrative Comp Physiol 271: R25-R33, 1996.

15. Mendel CM. The free hormone hypothesis: a physiologically based mathematical model. Endocr Rev 10: 232-274, 1989.

16. Panaretto BA, Paterson JYF, and Hills F. The relationship of the splanchnic, hepatic and renal clearance rates to the metabolic clearance rate of cortisol in conscious sheep. $J$ Endocrinol 56: 285-294, 1973.

17. Panaretto BA and Vickery MR. The rates of plasma cortisol entry and clearance in sheep before and during their exposure to a cold, wet environment. J Endocrinol 47: 273$285,1970$.

18. Paterson JYF and Harrison FA. The specific activity of plasma cortisol in sheep during continuous infusion of [1,2${ }^{3} \mathrm{H}_{2}$ ]cortisol, and its relation to the rate of cortisol secretion. $J$ Endocrinol 37: 269-277, 1967.

19. Schelcher F, Picard-Hagen N, Laroute V, Gayrard V, Popot MA, Andreoletti O, and Toutain PL. Corticoid concentrations are increased in the plasma and urine of ewes with naturally occurring scrapie. Endocrinology 140: 2422-2425, 1999. 
20. Soding P, Coghlan JP, Denton DA, Graham WF, Humphery TJ, and Scoggins BA. The effect of ACTH on the blood clearance rate of aldosterone, cortisol, $17 \alpha, 20 \alpha$-dihydroxy-4pregnen-3-one in the sheep. J Steroid Biochem 18: 173-177, 1983.

21. Tait JF and Burnstein S. In vivo studies of steroid dynamics in man. In: The Hormones, edited by Pincus G, Thimann KV, and Astwood EB. New York, NY: Academic, 1964, vol. 5, p. 441-557.

22. Toutain PL, Lefebvre HP, and King JN. Benazeprilat disposition and effect in dogs revisited with a pharmacokinetic/phar- macodynamic modeling approach. J Pharmacol Exp Ther 292: 1087-1093, 2000.

22a.Wagner JG Nonlinear pharmacokinetics. In: Fundamentals of Clinical Pharmacokinetics. Hamilton, IL: Drug Intelligence Publications, 1975, p. 271-281.

23. Yamaoka K, Tanigawara K, Nakagawa T, and Uno T. A pharmacokinetic analysis program (Multi) for microcomputer. J Pharmacobiodyn 4: 879-889, 1981.

24. Zumoff B, Fukushima DK, and Hellman L. Intercomparison of four methods for measuring cortisol production. J Clin Endocrinol Metab 38: 169-175, 1973.

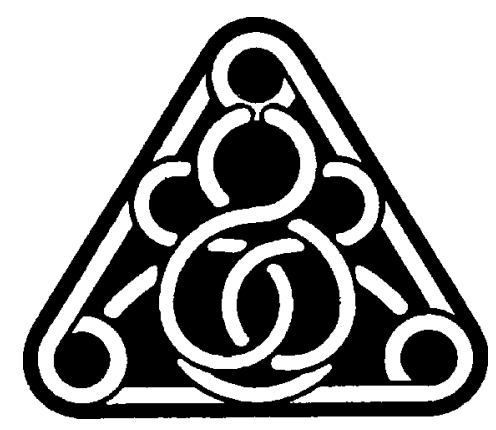

